\title{
Oral Theory and the Limits of Formulaic Diction
}

\author{
Margalit Finkelberg
}

\section{Introduction}

It has been pointed out more than once that the theory of formulaic composition in the form originally given it by Milman Parry is far from homogeneous. ${ }^{1}$ Not only chronologically but also in content Parry's studies of the Homeric formulae fall into two parts: the French publications of the 1920s and the American publications of the 1930s. In the former, Parry showed, first, that there are formulae and formulaic systems in Homer, and second, that they are characterized by extension and economy. He identified the style he thus described as "traditional." It is only in the American publications of the 1930s that he introduced the hypothesis that the formulaic character of the Homeric style is to be explained by its being the characteristic style of oral composition. A by-product of this development was that for all practical purposes "oral" became identified with "formulaic," giving rise to the widespread view that $100 \%$ orality amounts to $100 \%$ formularity. From then on, to claim that Homeric diction is oral-traditional has become equivalent to claiming that all of Homer consists of formulae.

As is well known to every student of Homer, neither Parry's definition of formula nor the rules of repetition, economy, and extension that he introduced would apply equally to all Homeric expressions. This fact became obvious to Parry himself as soon as he moved from noun-epithet combinations to other parts of Homeric diction. A partial solution that he proposed was, first, to introduce the notion of so-called "formulaic expressions," that is, such modifications of the traditional formulae that adapt them to situations not provided for in the poet's stock of traditional phrases; and, second, to approach all the unique expressions that cannot be accounted for in this way as underrepresented formulae. But even when both formulaic expressions and underrepresented formulae are taken into

1 See, e.g., Hoekstra 1965:10-12, Holoka 1991:457-60, Sale 1996:377, Foley 1997:147-49, and Bakker 1999:166-67. 
account, this would not change the fact that, insofar as one proceeds from Parry's definition of the formula, the claim that $100 \%$ of Homer is formulaic is highly problematic.

A priori, there were two ways out of this difficulty: (a) to abandon the idea of $100 \%$ formularity in Homer, or (b) to loosen the criteria for identifying the basic unit of Homeric composition so that they may apply equally to all Homeric expressions. Yet insofar as in the minds of most scholars "oral" became equivalent to "formulaic," adopting (a) would have amounted to recognizing that while some parts of Homer are oral others are not. This is why both Parry himself and his disciples Albert Lord and J. A. Notopoulos chose the other option, with most of the Parryists following their lead. As a result, not only single words regularly placed in the same metrical positions but also recurring syntactic and phonic patterns not identical in their wordings gradually began to be treated as formulae. Soon enough, the tendency to stretch the definition of the formula so that it might apply equally to all Homeric expressions began to be felt unsatisfactory by many. This led to the efforts, discussed in detail below, to replace the formula with another, more flexible, unit of composition.

In all this, it has largely been overlooked that abandoning the original definition of the formula while preserving the thesis of the oral character of Homeric composition inevitably leads to a fallacy, for the simple reason that the only foundation we have for the hypothesis of oral composition of the Homeric poems is the Homeric formula as identified by Parry. ${ }^{2}$ This fallacy is characteristic of those recent developments in Homeric scholarship that seek to modify the formula in such a way that it is replaced by other entities that are ostensibly more apt to supply a unified explanation for the totality of the Homeric text. In Section I of this paper, I will dwell on two such developments, both of them issuing from the application of contemporary linguistic theories to the phenomenon of Homeric language - the "generative approach" launched by Michael Nagler (1967 and 1974) and the "nucleusperiphery" theory introduced by Edzard Visser (1987 and 1999) and further developed by Egbert Bakker (1999; cf. Bakker and Fabbricotti 1999). In Section II, I will try to examine the possibilities offered by the alternative view, namely, that the text of Homer does not lend itself to a uniform explanation in terms of the formulaic theory.

${ }^{2}$ The Parry-Lord theory of oral composition differs from other theories of oral transmission of the Homeric poems — such as, e.g., the memorization theory, posited as a basis for an oral Homer long before Parry-in that it approaches the oral-traditional poem, or the "song," as being composed anew at the time of performance. On memorization see Pelliccia 2003. 


\section{Revisionist Approaches to Oral-Formulaic Theory}

Nagler, whose approach was closely associated with the generative linguistics of Noam Chomsky, adopted the tendency, first introduced by Parry himself, of loosening the criteria for identification of the formula, and took it further. He famously proposed "to abandon the word 'formula,' which means different things to different people, in favor of an entirely new concept" (1974:11). This new concept was that of a "preverbal Gestalt," or an underlying deep structure actualized in the surface structures of the spoken language (Nagler 1967:282-83). Technically, this meant that, in addition to the semantic and metrical criteria on the basis of which the formula had originally been identified by Parry ("an expression regularly used, under the same metrical conditions, to express an essential idea" [1971:13]), the generative approach introduced an additional criterion, that of resemblance in sound, thus turning the formula into "a highly suggestive associative pattern of sound and sense" (Nagler 1974:4) or, as one of Nagler's followers had it, "the nexus of rhythmic, phonic, and thematic associations" (A. Edwards 1988:25).

It is immediately obvious that what we have here is not so much two different interpretations of the formula as two different concepts of what should be taken as the basic unit of Homeric composition. According to Parry's original definition of the formula, such a unit should be identified on metrical and semantic grounds, whereas Nagler identified his basic unit on the grounds of rhythmic, semantic, and phonic criteria. The result was not just a modification of Parry's original definition of the formula but an entirely different concept of the process of formulaic composition. This becomes especially obvious as one proceeds from the minimal unit of a formula to formulaic systems, the larger categories into which Parry's formulae are organized.

The formulaic system is a group of expressions of varying metrical shape, specialized for rendering a given idea under various metrical conditions. In that they make it possible for the poet to express the idea he needs in various parts of the verse, the formulaic systems can justly be treated as the central core of the formulaic composition. Thus, for example, the idea "one's thumos ('spirit') orders one to do something" is covered by the following series of formulae running from the beginning of the verse up to the bucolic diaeresis:

$$
\begin{aligned}
& \text { - - - } \\
& \text { "the spirit in one's breast orders" }
\end{aligned}
$$

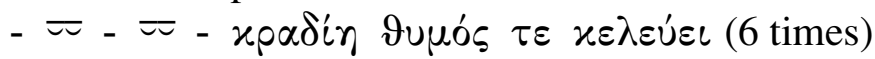

$$
\begin{aligned}
& \text { "the heart and spirit order" }
\end{aligned}
$$




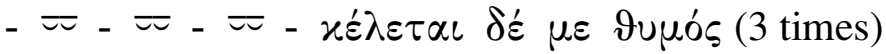

$$
\begin{aligned}
& \text { "the spirit orders me" }
\end{aligned}
$$

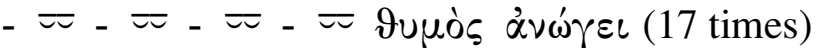

$$
\begin{aligned}
& \text { "the spirit commands." }
\end{aligned}
$$

We can see that the formulaic system at the poet's disposal allows him, by employing two synonymous verbs, $\chi \varepsilon \lambda \varepsilon v^{\prime} \omega$ and $\alpha \nu \omega \gamma \alpha$, to express the idea "one's thumos orders one to do something" in any part of the verse. Now such a system can never be arrived at on the basis of Nagler's criteria, for the simple reason that the verbs $\chi \varepsilon \lambda \varepsilon v^{\prime} \omega$ and $\alpha^{\prime} \nu \omega \gamma \alpha \alpha$ neither resemble each other in respect of sound nor necessarily occupy the same part of the verse. According to the criteria of the generative approach, the expression

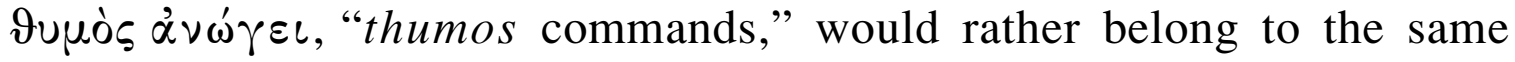

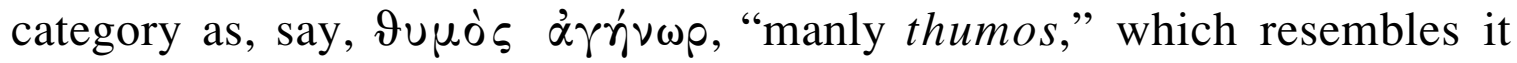
phonetically and is usually found in the same metrical position. That is to say, the significative value of the formula, essential as it is to Parry's theory of formulaic composition, plays practically no part in Nagler's taxonomy. ${ }^{3}$

What is at issue here is not just a difference between two taxonomies. Parry's classification of the formulae on the basis of meaning was introduced not for its own sake but in order to explain the process of Homeric composition. Following the formulaic systems that he discovered, one will eventually arrive at a general picture of how the poet expresses a given idea using a limited number of differently shaped expressions that are close in their meanings. ${ }^{4}$ But what would our concept of the process of Homeric composition be like if we follow Nagler's units? The answer is that the introduction of the criterion of sound transforms Parry's unit of signification into an associative pattern in which signification plays only a subordinate part. Proceeding from such patterns we shall arrive, at best, at something on a par with associative lyrics, but never at narrative poetry.

This is not to say, of course, that the associative patterns beyond meaning do not exist or take no part in composition. However, to take them as units of composition is to ignore the fact that any composition is eventually a process of selection out of the infinite number of possibilities,

${ }^{3}$ As Sale (1996:398, n. 27) points out, the factor of sound was first introduced by Parry himself in his 1930 article "Homer and Homeric Style" (Parry 1971:266-324). However, the full text of the passage to which Sale refers makes it clear that Parry saw the factor of sound as not applicable to formulaic systems, and therefore as subordinate to the factor of meaning. See Parry 1971:323: "Here it [the sound] has followed the thought which the singers wished to express."

\footnotetext{
${ }^{4}$ As was done, for example, in Jahn 1987.
} 
including those offered by the associations emerging in the poet's mind. Whatever such associations may be, it is reasonable to suppose that the poet would choose only such that are semantically appropriate (which would of course be true of associative lyrics as well). To claim that the poet would behave otherwise amounts to claiming that it made no difference to him

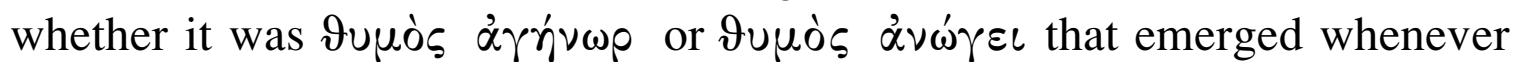
he intended to say "one's thumos orders one to do something." In other words, the associations favored by the partisans of the generative approach are subordinate to the process of signification, and it is above all the significative value of such associations that controls their actualization or non-actualization in epic diction.

Again, least of all do I intend to claim that associative patterns beyond meaning do not exist or deserve no scholarly attention. Yet, though they can certainly throw much light on unconscious processes in the poet's mind, these patterns cannot effectively account for the process of Homeric composition. Studying the associative patterns and the psychological processes they imply is quite a different discipline, with a different unit to proceed from and objectives other than those pursued by Parry. That is to say, what is being dealt with here is not just a modification of Parry's original hypothesis nor even a far-reaching revision of it, but the introduction of an alternative hypothesis regarding the nature of Homeric composition. Insofar as it purports to account for the oral character of Homeric composition without at the same time adopting the identification of the formula on which the idea of oral composition is founded, this is a hypothesis that suffers from petitio principii.

Nagler's approach to Homeric formulae was especially influential in the 1970s and 1980s. In the late 1980s and 1990s, oral-formulaic theory was taken in a different direction by Visser and Bakker, who approached Homeric diction as first and foremost an act of communication and its stuff as "information to be versified by the epic singer" (Bakker 1999:169, 174). Thus, in an article summarizing his earlier analysis (1987) of phrases of the type "A killed B" Visser wrote (1999:376):

Homer did not use given word-blocks, his basis rather was the semantically functional single-word, which cannot be replaced by any other. In the process of versification in the imaginative rhythmical structure called "hexameter" .. . he proceeded in such a way that he first placed the semantically most important elements (in our example: the personal names) and then adapted to this basic structure material whose semantic content is likewise indispensable, but whose prosodic scheme is variable (in our example: the verb-forms and conjunctions). 
Visser's theory was taken further in a 1991 article by Bakker and Fabbricotti, who applied it to phrases of the type "A killed B with a spear" (see 1999). According to their modification of Visser's theory, the verbs of killing should be regarded as nuclear in respect of such expressions as, for example, the dative "with spear." When approached in this way, all the elements of Homeric diction would fall into one of the following categories: (a) the semantically functional "nucleus," without which the act of communication cannot take place, and (b) the semantically neutral "periphery," which is subordinate to the nucleus in that its essential function is "verse-technical;" it is here that the Homeric formulae belong. Bakker and Fabbricotti write in this connection (1999:385):

Peripheral elements are semantically neutral in that they may just be present or absent, there being no difference for the intended meaning of the combination nucleus-periphery. This is the logical consequence of the notion of peripherality: a peripheral element is peripheral precisely because it may be absent without more ado. And when it is present, it serves primarily a verse-technical, rather than a semantic role.

Although nobody would deny that Homeric diction delivers meaningful messages that in the last analysis rely on the rules of ordinary speech, ${ }^{5}$ it is highly doubtful that its primary function was to serve as a means of communication, or at least a means of communication in the straightforward sense ascribed to it in the nucleus-periphery theory. Thus, in contemporary literary theory the language of art is approached as an act of communication sui generis, in which the artistic form is possessed of a special communicative function that is complementary to the communicative function of ordinary speech (see, e.g., Lotman 1977). As far as Homer is concerned, it is above all what John Miles Foley has defined as the "traditional referentiality" of the Homeric language that fulfils this special communicative function (1997:170; cf. 1991:38-60):

[A] language marked by its archaisms and dialect mixture, as well as by its own distinctive array of "words," becomes the dedicated medium for the composition and reception of the poems. In its very idiosyncrasy, long misunderstood as a curious blend of forms fossilized into convenient building blocks, lies the secret to its success as a signifying instrument. This "way of speaking" designates a channel for communication, a precise wavelength for both the making and the receiving of Homeric epic. Far from being a limitation or an awkward hindrance that leads to a nodding

\footnotetext{
${ }^{5}$ See espec. recent work by Bakker 1997, M. Edwards 2002, and Minchin 2001.
} 
Homer, it is a uniquely empowering medium, full of traditional implication at every level.

Characteristically, the unit from which Visser proceeds is that of a single line commensurate with a sentence containing both the names of the killer and the killed and the verb of killing. Bakker and Fabbricotti extend this unit also to such cases where an expression "with spear" is placed in enjambment, that is, when it "fills the remaining first half of the verse in a situation where the second half is to be filled by the metrical determinants (the names of the victor and his victim)." ${ }^{6}$ The fact, however, is that Homeric descriptions of the act of killing are far from constrained by this format. Consider for example the following passage, which is quite typical of such descriptions (Il. 17.346-49):

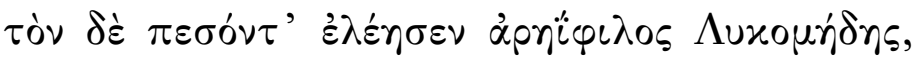

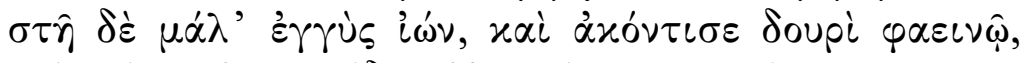

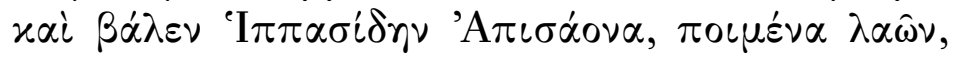

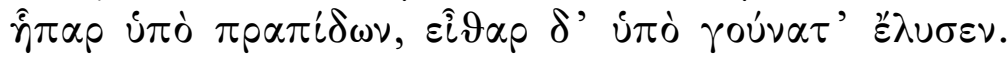

When he fell the warrior Lycomedes felt pity for him:

Going in close he took his stand and cast with his shining spear,

And hit Apisaon, Hippasus' son, shepherd of the people,

In the liver under the midriff, and instantly collapsed his strength. ${ }^{7}$

The act of killing is described here in four consecutive lines, of which the first delivers the name of the killer; the second introduces the act of hitting with a spear; the third gives the name of the killed; and the fourth refers to the act of killing as such. That is to say, not only is each of the socalled metrical determinants placed in a separate line but even the metrically variable and "peripheral" elements, the verb of killing and the expression "with spear," are each provided with separate lines of their own. It is difficult to see how such a lavish elaboration on the message "Lycomedes killed Apisaon" could have resulted from verse-technical constraints on the part of a poet communicating the given piece of information. In other words, there is good reason to believe that Homer was possessed of much

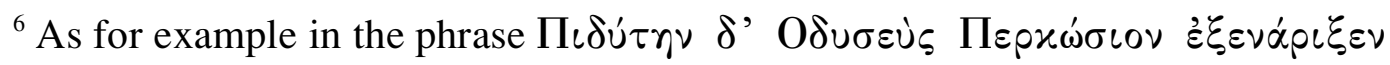
/ है $\gamma \chi \varepsilon \ddot{i} \chi \alpha \lambda x \varepsilon i \omega$ ("And Odysseus slew Pidytes, a man from Perkote, / with his spear of bronze"; Il. 6.30-31). See Bakker and Fabbricotti 1999:384.

${ }^{7}$ Trans. by Hammond 1987 (my italics). Cf. also Il. 5.610-17, where Aias kills Amphios, or Il. 11.575-79, where Eurypylos kills Apisaon, son of Phausiades. 
greater liberty in describing the act of killing than the "nucleus-periphery" theory would allow.

Furthermore, if we look at the entire gamut of Homeric descriptions of killing and wounding, the hierarchy of the nucleus and the periphery, which worked rather well on the level of the single verse-sentence, will be reversed. Rather often than not it is the formulaic patterns for throwing the spear, hitting the shield, and so on that are invariable, whereas the names of the participants vary. Thus, expressions of the type $x \alpha i \beta \alpha^{\prime} \lambda \varepsilon(\nu)$ 'A $A \tau \rho \varepsilon \dot{\imath} \delta \alpha o$

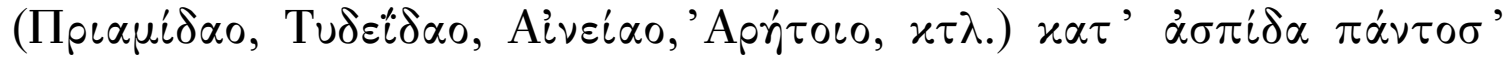
ध̈ or "of Aineas/Aretos") are obviously specialized for incorporating as many names as possible into the formulaic pattern describing the act of hitting someone's shield. ${ }^{8}$ In cases such as these, the "nucleus," i.e. the name of the man hit, would be subordinate to the "periphery," i.e. the formulaic patterns describing the act of hitting.

The main problem of the "nucleus-periphery" theory as I see it is the uncritical transferring of communicative aspects of ordinary speech to the language of poetry. It is not difficult to discern, however, that extrapolating the entire style of Homer from the unit on which the nucleus-periphery theory is based would result in a telegraph-like report of war casualties rather than the Homeric battle scenes as we know them. Small wonder, therefore, that the non-formulaic expressions are the only part of Homeric diction that the theory would effectively account for. Both the one-line expressions of the type "A killed B" studied by Visser and the so-called "expressions with referential potential," that is, those using the word "spear" beyond the standard situations prescribed by the battle scenes, studied by Bakker and Fabbricotti, belong to this category. All the rest is a huge periphery - a noise in the channel of communication, as it were-which is of no use in delivering nuclear information of any kind whatsoever. But this is exactly the sphere in which the poetic language of Homer or indeed any poetic language resides. In other words, the claim that all of Homer consists of nucleus and periphery, correct as it may well be on a purely linguistic level, does not do justice to the poetic style of Homer.

Just as in the case of the generative approach, the exponents of the nucleus-periphery theory proceed from the assumption of the oral character of Homeric composition without at the same time supplying an independent hypothesis by which this assumption could be substantiated. Yet to the extent that the theory seeks to replace the formulae, which are after all the only foundation available for the hypothesis of oral composition, by

${ }^{8}$ Il. 3.347, 356; 5.281; 7.250; 17.517; 20.274. 
alternative units of composition that are identified on entirely different grounds, the assumption of the oral character of Homeric composition is again left unsupported.

\section{The Applicability of the Theory of Formulaic Composition}

More than anything else, the ease with which revisionist approaches to the Homeric formula have succeeded in replacing traditional Parryism in the minds of so many scholars is indicative of the fact that traditional Parryism itself is undergoing a major crisis. It is symptomatic of the current situation that the number of scholarly publications on matters of formulaic analysis has sharply decreased, and the enthusiasm with which the essentials of the formulaic theory were being discussed in the 1960s has given way to an expressed fatigue and a defensive, if not apologetic, attitude. Paradoxically enough, one of the most important contributions to the ParryLord hypothesis since L'Épithète traditionnelle (Parry 1971:1-190; orig. publ. 1928) has been mainly responsible for this unwelcome development. I mean The Flexibility of the Homeric Formula by J. B. Hainsworth (1968).

Hainsworth's application of Parry's concept of formula to nounepithet combinations that are not proper names, which had been treated only incidentally in Parry's work, brought about several significant results. First, Hainsworth showed that the introduction of additional qualifications, which necessarily emerge when a given hypothesis' scope of evidence becomes considerably enlarged, renders Parry's hypothesis applicable to common nouns as well. This important conclusion has generally been overlooked. Second, he showed that Homer's diction is much more subtle and rich a phenomenon than could be inferred from the evidence of proper names. There was nothing in this conclusion to undermine the essentials of Parry's theory, and the extremely rich formulaic variations discovered by Hainsworth could be accounted for perfectly well along the lines of Parry's concept of formulaic modifications. True, Hainsworth's evidence demonstrated that there was an urgent need for a large-scale revision of the original concept of formulaic modification, but this is one of those things that happens when a hypothesis is being effectively developed. All this could have made the study of Homer's formulaic language even more rewarding; instead, the most conspicuous impact of Hainsworth's work on Homeric scholarship has been general bewilderment and the distinct impression that something is fundamentally wrong with Parry's hypothesis.

The revisionist atmosphere that became dominant after the appearance of Hainsworth's book has made most Homeric scholars overlook another 
significant consequence issuing from the application of the theory of formulaic composition to expressions that are not proper nouns. Namely, the studies of both Hainsworth and Arie Hoekstra have amply demonstrated that, insofar as one strictly follows Parry's definition of formula, it would be hard to avoid the conclusion that the gaps in the formulaic systems are too numerous to be ascribed to the chances of representation. ${ }^{9}$ To put it bluntly, there is insufficient evidence for asserting the thoroughly formulaic character of Homeric diction. Thus, according to Hainsworth's figures, the proportion of unique expressions among noun-epithet combinations containing the common rather than the proper nouns ranges from one-third to one-half - the proportion that, as Hainsworth himself remarked, is "disturbingly high in a diction commonly supposed to be entirely formulaic" (1962:66), whereas Hoekstra, proceeding from his own evidence, stated unequivocally that "it is practically out of the question that Homer's diction is wholly formulaic and traditional" (1965:24; cf. 15-16). ${ }^{10}$ Similar conclusions were also reached later in the studies of Mario Cantilena (1982), W. Merrit Sale (1989 and 1996:385), and Finkelberg (1989). As a result, today we can claim with a considerable degree of certainty that at least onethird of the Homeric corpus consists of individual expressions, that is, expressions that are both unique and not modeled on formulaic patterns.

This brings us back to the problem of the limited applicability of the theory of formulaic composition with which I started this paper. We have seen that there are two possible solutions to this problem: either (a) to abandon the dogma of the $100 \%$ formularity of Homer; or (b) to try to save it by loosening the criteria by means of which the basic unit of Homeric composition is identified. As I hope to have shown, sticking fast to the idea of $100 \%$ formularity is not only ruinous for oral-formulaic theory, in that it eventually leads to replacing the formula with other units that undermine the principles on which oral-formulaic theory is based, but also fallacious, in that it sticks to the hypothesis of oral composition even after the theoretical basis for such a hypothesis has been removed. In view of this, adopting the position of those who propose to abandon the idea of $100 \%$ formularity seems to be the only methodologically valid solution at hand.

We have seen that the unwillingness to abandon the idea that all of Homer consists of formulae is mainly due to the prevailing assumption that for all practical purposes "oral" is identical to "formulaic." Thus, Bakker and Fabbricotti, while criticizing attempts at loosening the criteria for

\footnotetext{
${ }^{9}$ See Hainsworth 1968:72-73 and Hoekstra 1965:15-16; cf. Pope 1963:12-13.

${ }^{10}$ For figures, see Hainsworth 1964:155-64; cf. 1968:13.
} 
identification of the formula, nevertheless reject the solutions proposed by Hainsworth and Hoekstra as "not necessary at all and even false," simply because "the way out of the problem pointed out by the above studies is to question the degree of orality and formularity in the Homeric poems" (1999:382, n. 3). On the other hand, scholars who, like Jasper Griffin or Rainer Friedrich, do not unreservedly support the hypothesis of the oral character of the Homeric poems tend to use the equation between orality and formularity for questioning the extent to which the text of Homer as we have it should be considered oral. ${ }^{11}$ But are the nonformulaic and the oral indeed as mutually exclusive as many are inclined to believe?

As studies of the contexts in which both the formulaic and the nonformulaic expressions emerge have shown, there is a clear functional specialization between these two categories of Homeric expressions. As distinct from the formulae and formulaic expressions, the nonformulaic expressions not only cannot be shown to be modeled on formulaic patterns but are also regularly employed in untypical narrative situations. Thus, to take my own study of Homeric expressions for joy as an example, instead of evenly covering all possible situations requiring an expression of joy, the formulaic system for this idea provides only (a) expressions that represent the joy that springs from hearing or seeing something cheerful-these expressions are cast in the third person of the aorist indicative and occur in every portion of the verse; and (b) expressions that describe joy as a feeling accompanying the main action-these expressions are cast in the imperfect and occur in the second half of the verse. As for other expressions of joy, I previously concluded (1989:196) that "all other situations in which joy might be expressed constitute one huge 'gap'. . . though this gap can occasionally be filled with modifications of formulaic patterns, it is most commonly filled with nonformulaic expressions: this is their primary function."

How can a nonformulaic expression be identified? Let us consider for example the expression $\vartheta \alpha^{\prime} \lambda \alpha \sigma \sigma \dot{\alpha} \quad \tau \varepsilon \dot{\eta} \chi \dot{\eta} \varepsilon \sigma \sigma \alpha$ ("and the roaring sea"; Il. $1.157)$, the very one of which Dorothea Gray once commented that "it is

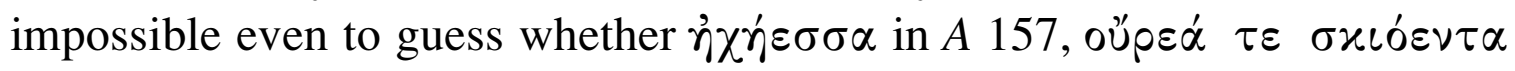
$\vartheta \dot{\alpha}^{\prime} \lambda \alpha \sigma \sigma \dot{\alpha} \tau \varepsilon \dot{\eta} \chi \hat{\eta}^{\prime} \varepsilon \sigma \sigma \alpha$, is the sole survival of a traditional phrase or a new creation" (1947:111; cf. Finkelberg 1989:195-97). Yet, as Gray herself

11 Griffin 1995:32-35; Friedrich, personal communication. But see already Hoekstra (1965:16): "Since, then, the supposition that Homeric poetry is wholly formulaic is at all events unprovable (if not entirely unsound), it cannot lend support to the view that the Iliad and the Odyssey are oral compositions." 
showed, the group of formulaic expressions for sea lacks a formula in the nominative: all of the nominative expressions for sea are unique. The reason for this becomes clear if we reflect that the idea "sea" usually appears in contexts such as "to sail across the sea," "to come to the seashore," and the like, none of which requires the nominative case. Moreover, the idea "the sea divides," which is the original context of $\vartheta \alpha^{\prime} \lambda \alpha \sigma \sigma \dot{\alpha} \tau \varepsilon \dot{\eta} \chi \dot{\eta} \varepsilon \sigma \sigma \alpha,{ }^{12}$ is hardly an idea that the epic poets would need to express as frequently as, say, "to sail across the sea." Since the phrase is not related to an attested formulaic pattern, is found in the case that is not represented in the formulaic system for sea, and expresses an unusual idea, it seems reasonable to infer that $\vartheta \alpha^{\prime} \lambda \alpha \sigma \sigma \alpha^{\prime} \tau \varepsilon \dot{\eta} \chi \hat{\gamma}^{\prime} \varepsilon \sigma \sigma \alpha$ is a nonformulaic expression rather than an underrepresented formula.

Now if the function of nonformulaic expressions was to fill the gaps in the formulaic systems, this can well mean that the nonformulaic elements in Homeric diction were complementary to the formulaic ones. This relationship can be consistently accounted for by the application of the same principle of economy on which Parry based his theory of formulaic composition. That is to say, just as it makes sense in terms of formulaic economy to have formulae and formulaic systems for any frequently recurring idea and standard narrative situation, so it equally makes sense not to overload the poet's memory in the case of ideas and situations that do not fall into this category, leaving room for the creation of individual expressions instead. As Maurice Pope (1963:9) put it, "it is easy to see how an equipment of formulae complete enough to meet the demands of every emergency might exceed the creative capacity of any individual singer." 13

The comparative evidence at hand also suggests that the recognition of the fact that nonformulaic expressions are germane to Homeric diction is not incompatible with the hypothesis that the Homeric poems were orally composed. Thus, according to Sale (1996:385), only about 65\% of The Wedding of Smailagić Meho by Avdo Mededović can be considered formulaic, while John D. Smith supplies the following figures for the epic of Pabuji (1991:26): ${ }^{14}$

${ }^{12}$ Achilles is explaining to Agamemnon that he has no feud with the Trojans (Il.

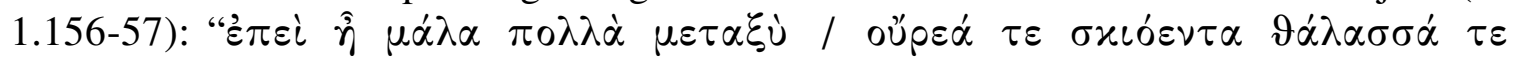
$\dot{\eta} \chi \dot{\eta} \varepsilon \sigma \sigma \alpha$ " ("since between us there lie / both many shadowy mountains and the roaring sea"). As Griffin (1986:53-54) has shown, the expression is part of a passage whose language is highly individual.

${ }^{13}$ Cf. Hoekstra 1965:15-16 and Hainsworth 1968:114.

${ }^{14}$ I am grateful to David Shulman for drawing my attention to this publication. 
In terms of approximate percentages, this means that in two performances by two sets of epic singers who are unrelated, who live at some distance from each other, and who have never met, $23 \%$ of the text sung is held identically in common, $18 \%$ is equivalent, and $36 \%$ is composed of formulae known to both sets of performers .... Only $23 \%$ can be said to be truly unique to one or the other performance.

This is not to say that comparative evidence alone can serve as conclusive proof that nonformulaic expressions belong with oral rather than literary composition. The caveat expressed by Hoekstra (1965:25), perhaps the most methodologically rigorous of all students of the Homeric formula, that "it is uncertain whether the Iliad and the Odyssey were composed orally," seems to be in place here. ${ }^{15}$ Hoekstra's caveat equally concerned nonformulaic and formulaic expressions, his claim having been that the use of formulae may be characteristic of both genuinely oral composition and such literary composition that, like the Posthomerica of Quintus of Smyrna, worked by way of deliberate imitation of traditional technique. This part of his argument has been effectively refuted by Sale, who showed (without, however, specifically referring to Hoekstra) that, though Quintus did use traditional formulae, he failed to employ such a hallmark characteristic of oral composition as formulaic systems. ${ }^{16}$ Defining the status of the nonformulaic expressions would require a separate examination. As far as I can see, such an examination should include, among other things, a comprehensive study of the ratio of metrical irregularities in this group of Homeric expressions. It is reasonable to suppose that the so-called metrical irregularities, frequently occurring as they do in Homer's modifications of traditional formulae, are a necessary by-product of oral composition, in that they can consistently be accounted for as resulting from the poet's need to adjust the traditional formulae to nontraditional contexts at the time of extempore composition. ${ }^{17}$ It follows, then, that the presence of metrical irregularities in nonformulaic expressions can serve as a test of their orality. However that may be, the only thing of which we can be certain at this stage

${ }^{15}$ Cf. Hoekstra's comment (1965:18): “Of course the objections I have raised against the argument do not prove that the hypothesis is untenable. Personally I believe that it is not impossible."

${ }^{16}$ See Hoekstra 1965:16-17 and Sale 1996.

${ }^{17}$ Cf. Parry 1971:196, 237; Hoekstra 1965:9-10; Finkelberg 1988 and 1997. 
is that these expressions constitute an inseparable part of Homeric diction as we know it.

The ensuing vision of Homeric diction would thus be that of a continuum or, as Joseph Russo put it in his 1997 assessment that incorporated the results of recent studies of nonformulaic elements in Homer, "an amalgam of elements covering a spectrum from highly formulaic to nonformulaic, a view that may be considered both unsurprising and uncontroversial" (259). ${ }^{18}$ The alternative to this view would be to abandon Parry's principles of repetition, economy, and extension, principles meant to account for the way in which the same meaning can be rendered by a limited number of traditional expressions, and to adopt revisionist theories whose practical usefulness for the concrete analysis of the text of Homer is far from conclusive. ${ }^{19}$ It is too often forgotten, indeed, that the explicative value of Parry's hypothesis of formulaic composition has proved its worth in the work of many scholars whose main interest was not so much the formulaic theory as such but, rather, the study of a given traditional Greek text cast in hexameters. To claim that the formulaic theory does not work, insofar as it cannot be indiscriminately applied to the totality of the text of Homer, is to ignore the fact that its application in the course of the last 70 years has changed the face of Homeric scholarship almost beyond recognition. This being the case, it would be an unforgivable mistake to abandon the approach that has contributed so much to our understanding of Homeric diction. ${ }^{20}$

Tel Aviv University

${ }^{18}$ Cf. M. Edwards 1997:269-72. At the same time, such a supposedly representative collection as de Jong 1999 ignores this development altogether.

${ }^{19}$ See, e.g., Russo on the generative approach (1997:252): "While the formulation makes elegant theory, it renders our concordance-compiled repetitions of limited use in finding the allomorphs of any Gestalt, leaving us with no investigative tool as a replacement except for each individual researcher's 'nose' for formulas."

${ }^{20}$ An earlier version of this paper was read at the conference "Oral Performance and Its Context," held at the University of Melbourne in July 2002. I would like to express my thanks to Chris Mackie, the convenor. As far as the present version is concerned, I am much indebted to the criticism and discussion of Thomas Hubbard, Toph Marshall, and Steve Nimis. I am also grateful to Rainer Friedrich for having allowed me to read sections from his forthcoming book on Homeric formulae and to the anonymous referee of this journal for his/her helpful remarks. 


\section{References}

Bakker 1997

Bakker 1999

Bakker and Fabbricotti 1999

Cantilena 1982

de Jong 1999

A. Edwards 1988

M. Edwards 1997

M. Edwards 2002

Finkelberg 1988

Finkelberg 1989

Finkelberg 1997

Foley 1991

Foley 1997
Egbert J. Bakker. Poetry in Speech: Orality and Homeric Discourse. Ithaca: Cornell University Press. 1999:163-83.

. "Homer and Oral Poetry Research." In de Jong

and Florence Fabbricotti. "Peripheral and Nuclear Semantics in Homeric Diction." In de Jong 1999:382-400. [Orig. publ. in Mnemosyne, 44 (1991):6384.]

Mario Cantilena. Per uno studio della formularità degli Inni Omerici. Rome: Edizioni dell'Ateneo.

Irene J. F. de Jong, ed. The Creation of the Poems. Vol. 1 of 4 in Homer: Critical Assessments. New York: Routledge.

Anthony T. Edwards. "K $\Lambda \mathrm{EO} \Sigma \mathrm{A} \Phi \Theta \mathrm{ITON}$ and Oral Theory." Classical Quarterly, 38:25-30.

Mark W. Edwards. "Homeric Style and Oral Poetics." In Morris and Powell 1997:261-83. - Sound, Sense, and Rhythm: Listening to Greek and Latin Poetry. Martin Classical Lectures. Princeton: Princeton University Press.

Margalit Finkelberg. "A Note on Some Metrical Irregularities in Homer." Classical Philology, 83:206-11.

Homer." Classical Philology, 84:179-97. "Homer, a Poet of an Individual Style." Scripta Classica Israelica, 16:1-8.

John Miles Foley. Immanent Art: From Structure to Meaning in Traditional Oral Epic. Bloomington: Indiana University Press.

and Powell 1997:146-73. 
Gray 1947

Griffin 1986

Griffin 1995

Hainsworth 1962

Hainsworth 1964

Hainsworth 1968

Hammond 1987

Hoekstra 1965

Holoka 1991

Jahn 1987

Latacz 1979

Minchin 2001

Morris and Powell 1997
Dorothea H. F. Gray. "Homeric Epithets for Things." Classical Quarterly, 41:109-21. Rpt. in The Language and Background of Homer. Ed. by G. S. Kirk. Cambridge: W. Heffer, 1964. pp. 55-67.

Jasper Griffin. "Homeric Words and Speakers." Journal of Hellenic Studies, 106:36-57. ed. Iliad, Book Nine. Oxford: Clarendon Press.

J. B. Hainsworth. "The Homeric Formula and the Problem of its Transmission." Bulletin for the Institute of Classical Studies, 9:57-68. Rpt. in Latacz 1979: 368-86.

. "Structure and Content in Epic Formulae: The Question of the Unique Expression." Classical Quarterly, 14:155-64. . The Flexibility of the Homeric Formula. Oxford: Clarendon Press.

Martin Hammond, trans. and intro. Homer's The Iliad. Harmondsworth: Penguin.

Arie Hoekstra. Homeric Modifications of Formulaic Prototypes. Amsterdam: North Holland.

James P. Holoka. "Homer, Oral Poetry Theory, and Comparative Literature: Major Trends and Controversies in Twentieth-Century Criticism." In Zweihundert Jahre Homer-Forschung. Ed. by Joachim Latacz. Stuttgart: Teubner. pp. 456-81.

Thomas Jahn. Zum Wortfeld "Seele-Geist" in der Sprache Homers. Munich: Beck.

Joachim Latacz, ed. Homer: Tradition und Neuerung. Darmstadt: Wissenschaftliche Buchgesellschaft.

Elizabeth Minchin. Homer and the Resources of Memory: Some Applications of Cognitive Theory in the Iliad and the Odyssey. Oxford: Oxford University Press.

Ian Morris and Barry Powell, eds. A New Companion to Homer. Leiden: E. J. Brill. 


\section{MARGALIT FINKELBERG}

Lotman 1977

Nagler 1967

Nagler 1974

Parry 1971

Pelliccia 2003

Pope 1963

Russo 1997

Sale 1989

Sale 1996

Smith 1991

Visser 1987

Visser 1999
Jurji Lotman. The Structure of the Artistic Text. Trans. by Ronald Vroon. Ann Arbor: University of Michigan Press.

Michael N. Nagler. "Towards a Generative View of the Oral Formula." Transactions of the American Philological Association, 98:269-311.

- Spontaneity and Tradition: A Study in the Oral Art of Homer. Berkeley: University of California Press.

Milman Parry. The Making of Homeric Verse: The Collected Papers of Milman Parry. Ed. by Adam Parry. Oxford: Clarendon. Rpt. 1987.

Hayden Pelliccia. "Two Points About Rhapsodes." In Homer, the Bible, and Beyond: Literary and Religious Canons in the Ancient World. Ed. by Margalit Finkelberg and Guy G. Stroumsa. Jerusalem Studies in Religion and Culture, 2. Leiden: E. J. Brill. pp. 97-116.

M. W. M. Pope. "The Parry-Lord Theory of Homeric Composition." Acta Classica, 6:1-21. Rpt. in Latacz 1979: $338-67$.

Joseph Russo. "The Formula." In Morris and Powell 1997: 238-60.

W. Merrit Sale. "The Trojans, Statistics, and Milman Parry." Greek, Roman and Byzantine Studies, 30:341-410.

. "In Defense of Milman Parry: Renewing the Oral Theory." Oral Tradition, 11:374-417.

John D. Smith. The Epic of Pabuji: A Study, Transcription and Translation. Cambridge: Cambridge University Press.

Edzard Visser. Homerische Versifikationstechnik: Versuch einer Rekonstruktion. Frankfurt: Peter Lang.

"Formulae or Single Words? Towards a New Theory of Homeric Verse-Making." In de Jong 1999:36481. [Orig. publ. in Würzburger Jahrbücher, 14 (1988):2137.] 